\title{
Fungicidas cúpricos, cloretos de benzalcônio e composto bioativo liquído (Bokashi): fitotoxicidade e controle da seca dos ponteiros causada por Erwinia psidii em goiabeiras
}

\author{
Adriana Magali F.A. Rezende, Celso K. Tomita \& Carlos H. Uesugi \\ Departamento de Fitopatologia, Universidade de Brasília, 70910-900, Brasília, DF, Brasil \\ Autor para correspondência: Carlos H. Uesugi, e-mail: uesugich@unb.br
}

\begin{abstract}
RESUMO
Diferentes formulações de fungicidas cúpricos, cloretos de benzalcônio e de composto bioativo líquido foram testados para o controle da seca dos ponteiros causada por Erwinia psidii em goiabeira (Psidium guajava), observando-se os possíveis efeitos fitotóxicos. O experimento foi conduzido em pomar comercial de goiabeira das variedades Pedro Sato e Comum, no município de Brazlândia, DF. Os tratamentos constaram dos seguintes produtos/L de água: $5,0 \mathrm{~g}$ de sulfato de cobre (SC), 3,5 g de oxicloreto de cobre (OC), 3,0 g de hidróxido de cobre (HC), 3,0 mL de cloretos de benzalcônio (CB) e 20,0 mL de composto bioativo líquido (CBL). A fitotoxicidade foi avaliada em botões florais e frutos, em três estádios de desenvolvimento, e a incidência da doença, em 10 ramos de frutificação em cada quadrante da planta nos mesmos estádios. Na variedade Pedro Sato, em frutos de tamanho inferior a 15 mm não foram observados sintomas severos de fitotoxicidade, no entanto, na variedade Comum foi possível observar sintomas severos ocasionados pelos cúpricos; em frutos entre 16 e $30 \mathrm{~mm}$ e acima de $31 \mathrm{~mm}$, em ambas as variedades, foram observados sintomas moderados a severos, ocasionados principalmente pelo SC. No controle da doença, os tratamentos com SC, OC, HC e CBL foram mais eficientes na variedade Pedro Sato, enquanto o CBL foi mais eficiente na variedade Comum. Em ambas as variedades o CBL mostrou menor Área Abaixo da Curva de Progresso da Doença (AACPD).
\end{abstract}

Palavras-chave: Psidium guajava, bactéria, fungicida, bactericida.

\section{ABSTRACT}

Cupric fungicides, benzalconium chlorides and liquid bioactive compost (Bokashi): phytotoxicity and control of guava bacterial blight caused by Erwinia psidii

Different formulations of cupric fungicides, benzalconium chlorides and liquid bioactive compost were tested to observe their phytotoxicity in guava fruits (Psidium guajava) and control of bacterial blight caused by Erwinia psidii. The experiment was carried out in a commercial guava orchard with "Pedro Sato" and "Comum" varieties in Brazlândia, DF. The treatments were comprised of the following products/L of water: $5.0 \mathrm{~g}$ copper sulphate (SC); $3.5 \mathrm{~g}$ copper oxychloride (OC); $3.0 \mathrm{~g}$ copper hydroxide (HC); $3.0 \mathrm{~mL}$ benzalconium chlorides (CB); $20.0 \mathrm{~mL}$ liquid bioactive compost (CBL). Phytotoxicity was evaluated in flower buds and three stages of fruit development; disease incidence was evaluated in the same treatments, on 10 fruit-bearing branches in each quadrant of the plant. In the Pedro Sato variety, in fruits smaller than $15 \mathrm{~mm}$ in diameter, a few slight symptoms of phytotoxicity was observed, while in the Comum variety some severe symptoms caused by copper were observed. In fruits of both varieties between 16 and $30 \mathrm{~mm}$ and larger than $31 \mathrm{~mm}$, moderate to severe symptoms were observed, mainly induced by the SC. In the control of the disease, the treatments with SC, OC, HC and CBL were more efficient in the Pedro Sato variety, while CBL was most efficient in Comum. In both treatments CBL showed a smaller area under disease progress curve (AUDPC).

Keywords: Psidium guajava, bacterium, fungicide, bactericide.

\section{INTRODUÇÃO}

A goiaba (Psidium guajava L.), entre as frutas tropicais, apresenta grande importância econômica no Brasil, pois seus frutos possibilitam várias formas de aproveitamento, sendo atualmente, comercializados para consumo "in natura" (Gonzaga Neto et al., 2003). As altas

Parte da Dissertação de Mestrado do primeiro autor. Universidade de Brasília. Brasília DF. 2006. produtividades, que podem ser obtidas nos pomares são reduzidas pela ocorrência de várias doenças, entre elas a bacteriose ou seca dos ponteiros causada por Erwinia psidii Rodrigues Neto et al. (Junqueira, 2000).

Esta doença foi primeiramente descrita no ano de 1982, em goiabeiras nas regiões de Valinhos e Pindamonhangaba, Estado de São Paulo (Rodrigues Neto et al., 1987). Posteriormente, a doença foi encontrada nos Estados de Minas Gerais (Romeiro et al., 1993 e 2002), no Espírito Santo (Oliveira et al., 2000), no Distrito Federal (Junqueira et al., 2001; Uesugi et al., 2001). De acordo com Marques 
et al. (2007), não há registros de ocorrência da bacteriose em outros países; visto que, os testes de patogenicidade existentes são longos e dispendiosos, considerando que a bactéria após repicagens sucessivas pode levar a perda da patogenicidade ou se tornar atípica.

A doença afeta todas as partes da planta, sendo mais prejudicial às extremidades dos ramos novos, onde a brotação sofre murchamento súbito, tomando coloração escura. Os frutos e botões florais também são afetados, ficando escurecidos, necrosados, secos e mumificados (Ribeiro et al., 1985; Rodrigues Neto et al., 1987; Robbs \& Rodrigues Neto, 1999; Oliveira et al., 2000; Junqueira et al., 2001; Uesugi et al., 2001; Romeiro et al., 2002; Piccinin et al., 2005; Marques et al., 2007). Segundo esses autores, a incidência da doença em pomares de goiabeira está relacionada diretamente as condições de temperatura elevada, alta umidade relativa e por ferimentos causados por tratos culturais.

Para o controle da bacteriose, são recomendadas pulverizações preventivas com fungicidas cúpricos, a cada 15 dias, sendo o oxicloreto de cobre o único registrado atualmente com essa finalidade específica. Entretanto, aplicações de fungicidas cúpricos podem provocar fitotoxicidade nas folhas e nos frutos em desenvolvimento (Piccinin et al., 2005).

Fungicidas à base de cobre têm sido usados em plantas cultivadas, visando o controle de doenças por mais de 100 anos, sendo comum a sua recomendação para o controle de doenças bacterianas (Silva \& Lopes, 1995). Entretanto, há relatos de que estes produtos usados isoladamente, no controle da ferrugem da goiabeira (Puccinia psidii), provocam sintomas leves de fitotoxicidade nos frutos (Martinez \& Pereira, 1984). O composto bioativo líquido, também conhecido como biofertilizante e adubo líquido pode ser aplicado sobre o solo ou sobre a cultura, possui propriedades nutricionais para as plantas e reduz a incidência de doenças (Bettiol et al., 1997).

O presente trabalho teve por objetivo avaliar o efeito de diferentes formulações de fungicidas cúpricos, de cloretos de benzalcônio e do composto bioativo líquido (Bokashi líquido) na incidência da seca dos ponteiros da goiabeira causada por E. psidii e na expressão de sintomas de fitotoxicidade em botões florais e em frutos, em diferentes estádios de desenvolvimento.

\section{MATERIAL E MÉTODOS}

O experimento foi instalado em pomar comercial, com espaçamento de 2,5 x 6,0 m, de aproximadamente sete a oito anos de idade, localizado no município de Brazlândia DF, em 3/01/2006. As cultivares utilizadas foram Pedro Sato e Comum, distribuídas alternadamente.

\section{Avaliação da expressão de sintomas de fitotoxicidade em botões florais e frutos \\ O delineamento experimental foi o de blocos}

casualizados, com cinco tratamentos que constaram dos seguintes ingredientes ativos de fungicidas aplicados em 1 $\mathrm{L}$ de água e suas respectivas doses do produto comercial: sulfato de cobre, 5 g (500 g P.C./100 L de água); oxicloreto de cobre, 3,5 g (350 g P.C./100 L); hidróxido de cobre, 3 g (300 g P.C./100 L); cloretos de benzalcônio, $3 \mathrm{~mL}$ (300 mL P.C./100 L); composto bioativo líquido também conhecido como adubo líquido, $20 \mathrm{~mL}$ mais a testemunha (somente água). Cada tratamento contou com quatro repetições (considerando quatro quadrantes de uma planta, uma repetição). Os produtos foram aplicados com um pulverizador costal, pressurizado com $50 \mathrm{lb} / \mathrm{pl}^{2}$, dotado de bico cônico, vazio tipo D-2, ajustado para um volume de calda de $2 \mathrm{~L} /$ planta, em intervalos variando entre sete a dez dias. As pulverizações iniciaram-se a partir da primeira semana de janeiro, no estádio de floração e frutificação, sendo que a última pulverização foi realizada na terceira semana de março, perfazendo um total de doze aplicações. Os estádios de desenvolvimento dos frutos avaliados foram: 1- inflorescência ou frutos com diâmetro inferior ou igual a $15 \mathrm{~mm}$; 2- frutos pequenos com diâmetro entre 16 e $30 \mathrm{~mm}$; 3- frutos médios, com diâmetro maior ou igual a $31 \mathrm{~mm}$.

As avaliações da fitotoxicidade foram iniciadas sete dias após as primeiras pulverizações, sendo realizada avaliações semanais, durante 70 dias, onde o experimento foi encerrado. Foram marcados 10 botões e 10 frutos para cada um dos estádios de desenvolvimento pré-estabelecidos. O critério de avaliação foi a presença dos sintomas de fitotoxicidade, usando-se a escala de notas (Goes et al., 2004): 0 - ausência de sintomas; 1 - sintomas leves (frutos com leves pontuações diminutas, pouco perceptíveis, sem restrição ao mercado de frutas frescas); 2- sintomas moderados (frutos com pontuações pequenas e visíveis, porém aceitos com restrição para o mercado de frutas frescas); 3- sintomas severos (pontuações escuras bem visíveis, ocupando espaços variáveis nos frutos, rejeitados para o mercado de frutas frescas). Os dados obtidos foram analisados com auxílio do programa de estatística, SAS (SAS Inc., Cary NC, EUA, 1989) e as médias dos tratamentos comparadas pelo teste de Tukey a 5\% de probabilidade.

\section{Avaliação do controle da seca dos ponteiros em ramos de frutificação}

Para o estudo da incidência da seca dos ponteiros, foram utilizadas as mesmas plantas do estudo da fitotoxicidade. Dez ramos de frutificação em cada quadrante da planta foram etiquetados, e seu desenvolvimento foi acompanhado nas semanas subseqüentes. As avaliações consistiram em inspeção visual, dos $15 \mathrm{~cm}$ apicais, em intervalos semanais, após as aplicações de fungicidas e do composto orgânico, determinando-se o número de ramos sadios e com sintomas da doença durante 70 dias.

Pela plotação no tempo, foram obtidas as curvas de progresso da doença e as áreas abaixo da curva de progresso da doença (AACPD) (Shaner \& Finney, 1977). As análises estatísticas foram feitas com o programa usado no ensaio 
anterior. As médias dos tratamentos foram comparadas pelo teste de Duncan ou Tukey ao nível de 5\% de probabilidade.

\section{RESULTADOS}

$\mathrm{Na}$ variedade Pedro Sato, os produtos aplicados produziram os seguintes efeitos: o sulfato de cobre foi o mais prejudicial, pois embora não tendo provocado sintomas severos (nível 3) nas inflorescências ( $\leq 15 \mathrm{~mm}$ ) foi o único a provocar sintomas moderados nesse estádio $(2,50 \%)$, significativamente diferente no estádio de frutos pequenos para sintomas severos $(62,50 \%)$, atingindo quase a totalidade de frutos médios $(93,50 \%)$ com mais alto nível de fitotoxicidade. O hidróxido de cobre e oxicloreto de cobre provocaram sintomas leves (nível 1) nas inflorescências, resultado que é significativamente diferente dos demais níveis, mas que ainda não diferem da testemunha e de outros produtos. Ambos os produtos atingem o estádio de frutos médios provocando a maior percentagem de sintomas leves a moderados (nível 2), 38,25\% a 14,25\% e 42,75\% a 38,00\%, respectivamente (Tabela 1 ).

Para a variedade Comum, os produtos cúpricos mostraram fitotoxicidade em todos os estádios avaliados, para todos os níveis. O sulfato de cobre foi o mais prejudicial, apresentando sintomas severos em maior percentagem $(3,75 \%)$ desde a inflorescência, embora não tenha apresentado diferença significativa para os demais tratamentos. Nos estádios subseqüentes mostrou maior percentagem de sintomas severos com $40,50 \%$ e $91,00 \%$, respectivamente. $\mathrm{O}$ hidróxido de cobre, de todos os cúpricos foi o que causou menor fitotoxicidade, no que se refere aos sintomas severos em todos os estádios avaliados; entretanto, atingiu os estádios de frutos pequenos e médios provocando maiores percentagens de sintomas leves, $34,00 \%$ e $44,25 \%$, respectivamente. $\mathrm{O}$ oxicloreto de cobre foi o que apresentou maior percentagem de frutos médios com sintomas moderados (Tabela 2).

Em ambas as variedades, em todos os estádios avaliados, os tratamentos com cloretos de benzalcônio e composto bioativo líquido não causaram problemas de fitotoxicidade, no que diz respeito a sintomas moderados e severos, sendo significativamente semelhantes à testemunha (Tabela 1 e 2).

No controle da bacteriose, em ramos de frutificação de goiabeira, foi verificado que na variedade Pedro Sato, o tratamento com cloretos de benzalcônio foi semelhante à testemunha e demais tratamentos, sendo confirmado na AACPD, mostrando maiores destaques para os composto

TABELA 1 - Fitotoxicidade de diferentes formulações de defensivos em goiabas, da variedade Pedro Sato, em condição de campo

\begin{tabular}{|c|c|c|c|c|c|c|c|c|c|c|c|c|}
\hline \multirow{4}{*}{ Tratamentos } & \multicolumn{12}{|c|}{ Percentagem de frutos com fitotoxicidade } \\
\hline & \multicolumn{12}{|c|}{ Estádios dos frutos avaliados } \\
\hline & \multicolumn{4}{|c|}{ Inflorescência ( $\leq 15$ mm) } & \multicolumn{4}{|c|}{ Frutos pequenos $(16 \leq 30 \mathrm{~mm})$} & \multicolumn{4}{|c|}{ Frutos médios ( $\leq 31 \mathrm{~mm})$} \\
\hline & $0 *$ & 1 & 2 & 3 & $\mathbf{0}$ & 1 & 2 & 3 & $\mathbf{0}$ & 1 & 2 & 3 \\
\hline $\begin{array}{l}\text { Oxicloreto de } \\
\text { Cobre }\end{array}$ & $93,00 \mathrm{aA}$ & $7,00 \mathrm{bB}$ & $0,00 \mathrm{aC}$ & $0,00 \mathrm{aC}$ & $49,75 \mathrm{cA}$ & $30,25 \mathrm{aB}$ & $14,75 \mathrm{aC}$ & $5,25 \mathrm{bC}$ & $6,00 \mathrm{~dB}$ & $42,75 \mathrm{aA}$ & $38,00 \mathrm{aA}$ & $13,25 \mathrm{bB}$ \\
\hline Sulfato de Cobre & $84,00 \mathrm{bA}$ & $13,50 \mathrm{aB}$ & $2,50 \mathrm{aC}$ & $0,00 \mathrm{aC}$ & $15,00 \mathrm{~dB}$ & $5,75 \mathrm{cB}$ & $16,75 \mathrm{aB}$ & $62,50 \mathrm{aA}$ & $0,00 \mathrm{dC}$ & $0,75 \mathrm{cC}$ & $5,75 \mathrm{bcB}$ & $93,50 \mathrm{aA}$ \\
\hline $\begin{array}{l}\text { Cloretos de } \\
\text { Benzalcônio }\end{array}$ & $98,25 \mathrm{aA}$ & $1,75 \mathrm{bcB}$ & $0,00 \mathrm{aC}$ & $0,00 \mathrm{aC}$ & $91,25 \mathrm{aA}$ & $8,75 \mathrm{cB}$ & $0,00 \mathrm{bC}$ & $0,00 \mathrm{bC}$ & $80,50 \mathrm{bA}$ & $19,25 \mathrm{bB}$ & $0,25 \mathrm{cC}$ & $0,00 \mathrm{cC}$ \\
\hline $\begin{array}{l}\text { Composto } \\
\text { Bioativo Líquido }\end{array}$ & $99,50 \mathrm{aA}$ & $0,50 \mathrm{cB}$ & $0,00 \mathrm{aB}$ & $0,00 \mathrm{aB}$ & $99,50 \mathrm{aA}$ & $0,50 \mathrm{~dB}$ & $0,00 \mathrm{bB}$ & $0,00 \mathrm{bB}$ & $94,50 \mathrm{aA}$ & $5,50 \mathrm{cB}$ & $0,00 \mathrm{cC}$ & $0,00 \mathrm{cC}$ \\
\hline $\begin{array}{l}\text { Testemunha (sem } \\
\text { fungicida) }\end{array}$ & $99,00 \mathrm{aA}$ & $1,00 \mathrm{bcB}$ & $0,00 \mathrm{aB}$ & $0,00 \mathrm{aB}$ & $99,50 \mathrm{aA}$ & $0,50 \mathrm{~dB}$ & $0,00 \mathrm{bB}$ & $0,00 \mathrm{bB}$ & $94,75 \mathrm{aA}$ & $5,25 \mathrm{cB}$ & $0,00 \mathrm{cC}$ & $0,00 \mathrm{cC}$ \\
\hline
\end{tabular}

Médias seguidas da mesma letra, minúscula nas colunas e maiúscula nas linhas não diferem entre si, de acordo com o teste de Tukey, $5 \%$.

*níveis de fitotoxicidade (escala de notas segundo Goes et al., 2004):

0 - ausência de sintomas;

1- sintomas leves (pontuações diminutas, pouco perceptíveis, sem restrição ao mercado de frutas frescas);

2- sintomas moderados (pontuações pequenas e visíveis, porém aceitos com restrição para o mercado de frutas frescas);

3- sintomas severos (pontuações escuras bem visíveis, ocupando espaços variáveis nos frutos, rejeitados para o mercado de frutas frescas). 
Fungicidas cúpricos, cloretos de benzalcônio e composto bioativo liquído...

TABELA 2 - Fitotoxicidade de diferentes formulações de defensivos em goiabas, da variedade Comum, em condição de campo

Percentagem de frutos com fitotoxicidade

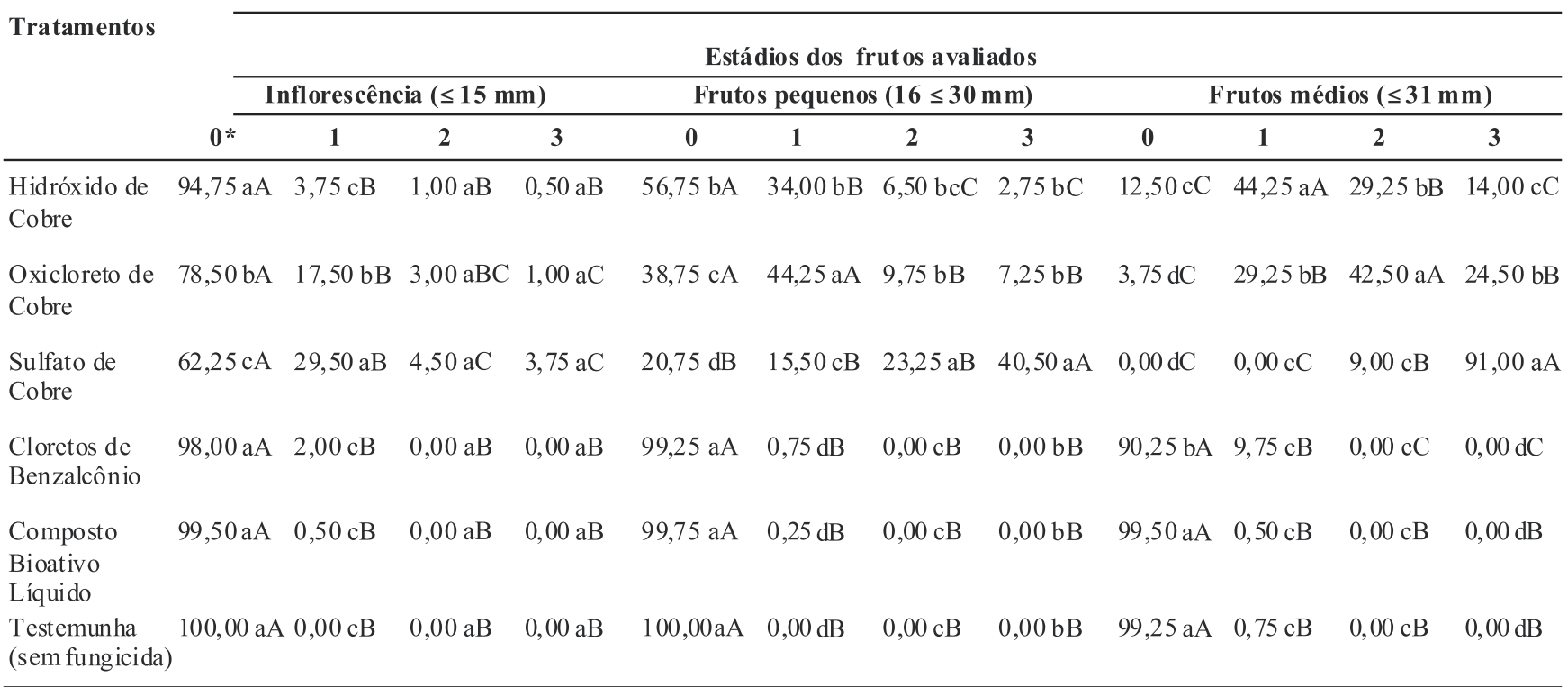

Médias seguidas da mesma letra, minúscula nas colunas e maiúscula nas linhas não diferem entre si, de acordo com o teste de Tukey, 5\%.

*níveis de fitotoxicidade (escala de notas segundo Goes et al., 2004):

0 - ausência de sintomas;

1- sintomas leves (pontuações diminutas, pouco perceptíveis, sem restrição ao mercado de frutas frescas);

2- sintomas moderados (pontuações pequenas e visíveis, porém aceitos com restrição para o mercado de frutas frescas);

3- sintomas severos (pontuações escuras bem visíveis, ocupando espaços variáveis nos frutos, rejeitados para o mercado de frutas frescas).

bioativo líquido, oxicloreto de cobre e sulfato de cobre. Já na variedade Comum, o composto bioativo líquido apresentou melhor controle da doença com $12,50 \%$ de ramos infectados, sendo estatisticamente semelhante ao hidróxido de cobre e diferenciando da testemunha e demais tratamentos, tendo inclusive menor AACPD (Tabela 3).

Analisando a curva de progresso da doença, foi verificado que na variedade Pedro Sato, todos os tratamentos com exceção dos cloretos de benzalcônio apresentaram menor progresso da doença até os 21 dias após o tratamento (DAT), comparado com a variedade Comum (Figura 1 e 2). No entanto, a testemunha da variedade Pedro Sato aumentou progressivamente a percentagem de ramos de frutificação infectados, chegando à última semana de avaliação apresentando mais de $50 \%$ de ramos infectados (Figura 1). Já na variedade Comum, foi verificado que todos os tratamentos, com exceção do composto bioativo líquido que manteve baixa a percentagem da doença, mostraram maiores percentagens de ramos infectados, com picos entre sete e 21 DAT, redução aos 28 DAT e posterior aumento gradativo até os 70 DAT (Figura 2).

\section{DISCUSSÃO}

Em geral, os tratamentos com cúpricos, em ambas as variedades, mostraram causar fitotoxicidade; embora diferindo quanto aos estádios avaliados e quanto aos níveis de fitotoxicidade. O sulfato de cobre foi o mais prejudicial, principalmente nos estádios de frutos pequenos (diâmetro entre $16 \geq 30 \mathrm{~mm}$ ) e os frutos médios (diâmetro $\geq 31 \mathrm{~mm}$ ) explicando a maior percentagem de frutos com sintomas severos de fitotoxicidade. Os resultados do presente trabalho corroboram os observados por vários autores como Martins (2006) que estudando o controle químico da ferrugem da goiabeira (Puccinia psidii) em condições de campo verificou que o oxicloreto de cobre não causou sintomas de fitotoxicidade nos frutos, visto que, foi pulverizado somente em fases nas quais os frutos apresentavam-se próximos de $2 \mathrm{~cm}$ e Goes et al. (2004) que observaram que frutos com diâmetro $\leq$ a $15 \mathrm{~mm}$, não apresentavam sintomas de fitotoxicidade e, em frutos com diâmetro entre 25 e 35 $\mathrm{mm}$, os sintomas severos foram detectados nos tratamentos com oxicloreto de cobre e hidróxido de cobre; nos frutos com diâmetro $\geq$ a $40 \mathrm{~mm}$, não foram observados sintomas severos.

Pressupõe-se que o nível moderado a severo de fitotoxicidade verificado no estádio de frutos médios, tratados com fungicidas cúpricos, deve-se ao grau de desenvolvimento dos frutos, já que esses se encontram em fase de maturação. Tais efeitos constituem-se num obstáculo à produção de frutos de alto padrão de qualidade, destinados ao mercado de frutas frescas.

Em relação às folhas das plantas, não foram observados sintomas de fitotoxicidade causados pelos 
A.M.F.A. Rezende et al.

TABELA 3 - Incidência de seca dos ponteiros em ramos de frutificação de goiabeira, pulverizados semanalmente com diferentes defensivos durante 70 dias, em campo

\begin{tabular}{|c|c|c|c|c|}
\hline \multirow{3}{*}{ Tratamentos } & \multicolumn{4}{|c|}{ Subtratamentos } \\
\hline & \multicolumn{2}{|c|}{$\%$ ramos infectados ${ }^{1}$} & \multicolumn{2}{|c|}{$\mathrm{AACPD}^{2}$} \\
\hline & Pedro Sato & Comum & Pedro Sato & Comum \\
\hline Cloretos de B enzalcônio & $31,2 \mathrm{ab}^{*}$ & $30,0 \mathrm{a}$ & $16,7 \mathrm{ab}$ & $12,7 \mathrm{ab}$ \\
\hline Sulfato de Cobre & $28,7 \mathrm{~b}$ & $35,0 \mathrm{a}$ & $9,4 \mathrm{~b}$ & $15,9 \mathrm{ab}$ \\
\hline Oxicloreto de Cobre & $27,5 \mathrm{~b}$ & 33,7 a & $9,8 \mathrm{~b}$ & $14,0 \mathrm{ab}$ \\
\hline Hidróxido de Cobre & $23,7 \mathrm{~b}$ & $26,2 \mathrm{ab}$ & $10,9 \mathrm{ab}$ & $12,8 \mathrm{ab}$ \\
\hline Composto Bioativo Líquido & $21,2 \mathrm{~b}$ & $12,5 \mathrm{~b}$ & $9,4 \mathrm{~b}$ & $7,3 \mathrm{~b}$ \\
\hline Testemunha & $51,2 \mathrm{a}$ & $38,7 \mathrm{a}$ & $17,9 \mathrm{a}$ & $19,4 \mathrm{a}$ \\
\hline CV $(\%)$ & 46,3 & 36,2 & 39,6 & 41,8 \\
\hline
\end{tabular}

*Médias seguidas da mesma letra na coluna não diferem entre si, de acordo com o teste de Duncan, $5 \%$.

1-Média de quatro repetições

2-Área abaixo da curva de progresso da doença (Shaner \& Finney, 1977).

\section{}

응

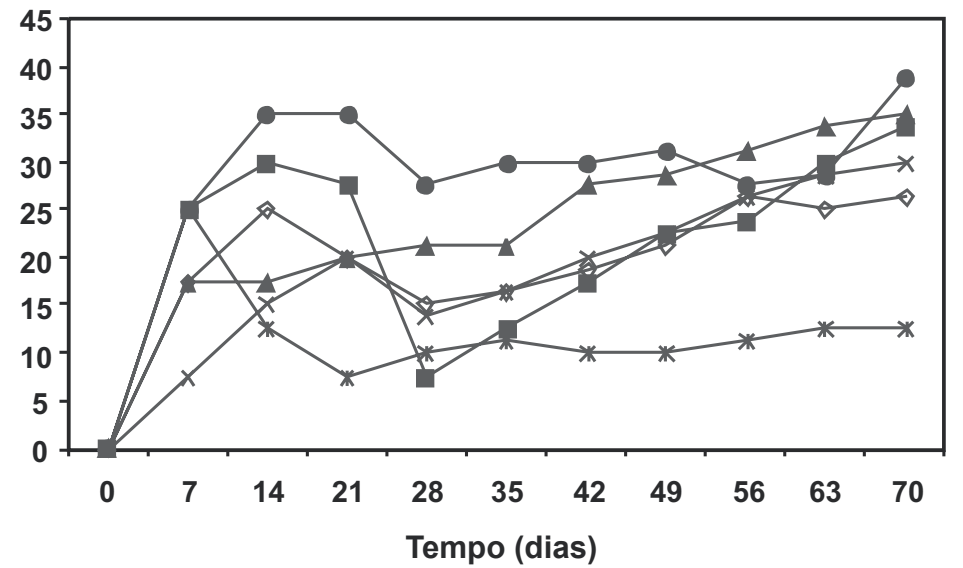

FIG. 1 - Curva de progresso da doença em goiabeiras variedade Pedro Sato, tratadas semanalmente com diferentes defensivos durante 70 dias, em campo.

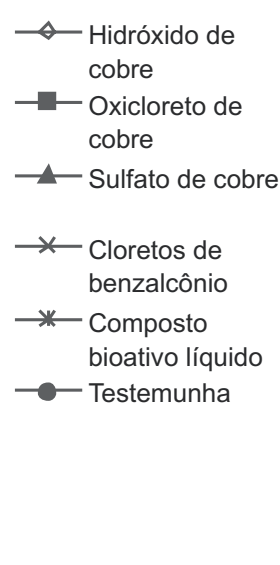

FIG. 2 - Curva de progresso da doença em goiabeiras variedade Comum, tratadas semanalmente com diferentes defensivos durante 70 dias, em campo. 
Fungicidas cúpricos, cloretos de benzalcônio e composto bioativo liquído...

cúpricos, confirmando os resultados de Goes et al. (2004). Embora com outros patossistemas, vários autores obtiveram resultados semelhantes: em cacaueiro (Theobroma cacao), quando usou-se o oxicloreto de cobre com 3,0 g i.a/planta para o controle do fungo Crinipellis perniciosa (Almeida et al., 2002); em meloeiro (Cucumis melo) quando usouse o hidróxido de cobre em $200 \mathrm{~g} / 100 \mathrm{~L}$ de água (Costa et al., 2006) e o oxicloreto de cobre $750 \mathrm{~g} / \mathrm{ha}$ (Sales Jr. et al., 2007), ambos no controle da "mancha aquosa" causada por Acidovorax avenae subsp. citrulli (Schaad et al.) Willems et al.

No que se refere ao controle da "Seca dos Ponteiros", com exceção do composto bioativo líquido que teve melhor desempenho na variedade comum, os cúpricos não se destacaram dos outros tratamentos. Entre as variedades, a Pedro Sato respondeu melhor aos tratamentos, sugerindo a influência de fatores genéticos nesse aspecto, pois, mesmo a testemunha tendo apresentado maior incidência da doença ao final do experimento, nas plantas tratadas foi relativamente menor que na variedade Comum. Embora não apresente diferença estatística o desempenho do sulfato de cobre foi inferior, para ambas a variedade, em relação ao oxicloreto de cobre e hidróxido de cobre, divergindo dos obtidos por Rezende et al. (2005) quando estudaram a sensibilidade "in vitro" de isolados de Erwinia psidii a diferentes formulações cúpricas, onde o sulfato de cobre mostrou melhor eficiência na inibição do crescimento para todos os isolados testados.

O oxicloreto de cobre e o hidróxido de cobre tem sido utilizado largamente para o controle de doenças de plantas. Martins (2006), verificou que duas aplicações do oxicloreto de cobre a $2.400 \mathrm{mg} / \mathrm{L}$, intercalados com fungicidas sistêmicos e mancozeb, na fase de botões florais e frutos com até $4 \mathrm{~cm}$ de diâmetro, foram praticamente suficientes para estabilizar por até 14 dias a ferrugem no campo. Resultados semelhantes a estes foram obtidos por Goes et al. (2004) estudando a eficiência dos fungicidas cúpricos no controle da ferrugem em goiaba, onde se verificou que os produtos a base de oxicloreto de cobre e hidróxido de cobre apresentaram baixa percentagem de frutos infectados. Estudo com outro patossistema, verificou que o hidróxido de cobre mostrou eficiência para a bactéria Acidovorax avenae subsp. citrulli (Costa et al., 2006). Esses dados corroboram os obtidos no presente trabalho, levando a concluir que, entre os cúpricos o sulfato de cobre não é um produto recomendável para a cultura da goiaba, sendo preferível o oxicloreto de cobre e hidróxido de cobre, observando logicamente algumas condições referidas acima.

O composto bioativo líquido mostrou ser bastante eficiente, onde em ambas as variedades apresentou menor AACPD. A utilização de compostos orgânicos tem sido ultimamente uma ferramenta de suma importância em várias culturas, elevando as suas produtividades. O uso dos resíduos orgânicos tem a finalidade de substituir os agrotóxicos, uma vez que a utilização continuada destes causam problemas à saúde humana, além de elevarem o custo da cultura. Os compostos orgânicos quando são incorporados ao solo trazem efeitos benéficos nas características físico-químicas do solo, funcionando como fertilizante orgânico. Assim sendo a incorporação dos compostos bioativos ou a pulverização dos produtos da biodigestão, induzem o aparecimento espontâneo de antagonistas de pragas e doenças, resultando no equilíbrio de todos os componentes do agroecossistema (Bettiol et al., 1997; Tomita, 2001), fatos estes também observados neste trabalho.

\section{AGRADECIMENTOS}

À Coordenação de Aperfeiçoamento de Pessoal de Nível Superior - CAPES pela concessão de bolsa de estudo durante o curso de mestrado do primeiro autor.

\section{REFERÊNCIAS BIBLIOGRÁFICAS}

Almeida OC, Almeida LCC, Bezerra JL (2002) Estudo de fungicidas a base de cobre no controle da vassoura-de-bruxa do cacaueiro no sudeste da Bahia. Agrotrópica 14:97-100.

Bettiol W, Migheli Q, Garibaldi A (1997) Controle com matéria orgânica do tombamento do pepino, causado por Pythium ultimum Trow. Pesquisa Agropecuária Brasileira 32:57-61.

Costa FM, Sales Jr. R, Almeida FA, Lopes MV (2006) Eficiência de kasugamicina e hidróxido de cobre no controle da bactéria Acidovorax avenae subsp. citrulli, agente causal da mancha-aquosa do meloeiro. Revista de Biologia e Ciências da Terra 6:132-138.

Goes A, Martins RD, Reis RF (2004) Efeito de fungicidas cúpricos, aplicados isoladamente ou em combinação com mancozeb, na expressão de sintomas de fitotoxicidade e controle da ferrugem causada por Puccinia psidii em goiabeira. Revista Brasileira de Fruticultura 26:1-8.

Gonzaga Neto L, Bezerra JEF, Costa RS (2003) Competição de genótipos de goiabeira (Psidium guajava L.) na região do submédio São Francisco. Revista Brasileira de Fruticultura 25:480-482.

Junqueira NTV (2000) Doenças e Pragas. In: Manica I (Ed.) Fruticultura Tropical 6 Goiaba. Porto Alegre. Cinco Continentes. pp. 225-270.

Junqueira NTV, Andrade LRM, Pereira M, Lima MM, Chaves RC (2001) Doenças da goiabeira no cerrado. Brasília DF. Embrapa SPI (Circular Técnica, 15).

Marques ASA, Coelho MVS, Ferreira MASV, Damasceno JPS, Mendes AP, Vieira TM (2007) Seca dos ponteiros da goiabeira causada por Erwinia psidii: níveis de incidência e aspectos epidemiológicos. Revista Brasileira de Fruticultura 29:488-493.

Martinez JM, Pereira FM (1984) Efeito de diferentes fungicidas no controle da ferrugem da goiabeira (Puccinia psidii Wint). In: Anais, 7. Congresso Brasileiro de Fruticultura. Florianópolis SC. pp. 519-523.

Martins MVV (2006) Danos à produção e o controle químico da ferrugem (Puccinia psidii) na cultura da goiabeira. Tese de Doutorado. Campos dos Goytacazes RJ. Universidade Estadual do Norte Fluminense Darcy Ribeiro.

Oliveira JR, Ventura JA, Silva IT, Costa H (2000) Ocorrência da 
bacteriose da goiabeira, causada por Erwinia psidii, no Estado do Espírito Santo. Fitopatologia Brasileira 25:328. (Resumo)

Piccinin E, Pascholati SF, Di Piero RM (2005) Doenças da Goiabeira (Psidium guajava). In: Kimati H, Amorim L, Rezende JAM, Bezerra Filho A, Camargo LEA (Eds.) Manual de Fitopatologia Vol. 2. Doenças das Plantas Cultivadas. $4^{a}$. Ed. São Paulo. Ceres. pp. 401-405.

Rezende AM, Miranda Filho RJ, Uesugi CH (2005) Sensibilidade de isolados de Erwinia psidii a diferentes formulações cúpricas. Fitopatologia Brasileira 30:76. (Resumo)

Ribeiro IJA, Sugimori MH, Rodrigues Neto J, Yamashiro T, Piza Jr CT, Prates HS, Frediani AJ (1985) A bacteriose da goiabeira. Coordenadoria de Assistência Técnica Integral (CATI) 231.

Robbs CF, Rodrigues Neto J (1999) Enfermidades causadas por bactérias em fruteiras tropicais no Brasil. Summa Phytopathologica 25:73-76.

Rodrigues Neto J, Robbs CF, Yamashiro T (1987) A bacterial disease of guava (Psidium guajava L.) caused by Erwinia psidii sp. nov. Fitopatologia Brasileira 12:345-350.

Romeiro RS, Moraes RMA, Oliveira Jr, Couto FAA, Rezende ST (1993) Uma enfermidade da goiabeira de etiologia bacteriana no Estado de Minas Gerais. Fitopatologia Brasileira 18:283. (Resumo)
Romeiro RS, Batista UG, Barbosa JG, Rodrigues Neto J (2002) Situação e perspectiva de controle da morte das pontas da goiabeira (Erwinia psidii) em Minas Gerais-Relato de um caso. Revista Ceres 49:329-334.

Sales Jr. R, Pontes Filho FST, Nunes GHS, Torres GRC (2007) Eficiência de acibenzolar-s-methyl e oxicloreto de cobre no controle de Acidovorax avenae subsp. citrulli, agente causal da "mancha-aquosa" no meloeiro. Revista de Biologia e Ciências da Terra 7:66-70.

SAS Institute (1989). SAS User's Guide, 4. Version 8. Cary NC.

Shaner G, Finney RE (1977) The effect of nitrogen fertilization on the expression of slow-mildewing resistance in knox wheat. Phytopathology 67:1051-1056.

Silva VL, Lopes CA (1995) Isolados de Pseudomonas syringae pv. tomato resistentes a cobre em tomateiros pulverizados com fungicidas cúpricos. Fitopatologia Brasileira 20:85-89.

Tomita CK (2001) O cultivo do morango orgânico In: Anais do I Workshop de Olericultura Orgânica na Região Agroeconômica do Distrito Federal, Brasília DF. pp. 119-124.

Uesugi CH, Melo Filho PA, Lima MLP, Tomita CK, Moraes CA, Café Filho AC, Ueno B (2001) Ocorrência de Erwinia psidii sobre goiabeira detectada no Distrito Federal. Summa Phytopathologica 27:118. (Resumo) 